\title{
Interferometric radar observations of Glaciar San Rafael, Chile
}

\author{
ERIC RIGNOT \\ Jet Propulsion Laboratory, California Institute of Technology, Pasadena, California 91109, U.S.A. \\ RICHARD FORSTER AND BRYAN ISACKS \\ Department of Geological Sciences, Cornell University, Ithaca, New York 14853, U.S.A.
}

\begin{abstract}
Interferometric radar observations of Glaciar San Rafael, Chile, were collected in October 1994 by NASA's Spaceborne Imaging Radar C (SIR-C) at both L- $(24 \mathrm{~cm})$ and C-band frequency $(5.6 \mathrm{~cm})$, with vertical transmit and receive polarization. The C-band data did not yield good geophysical products, because the temporal coherence of the signal was significantly reduced after $24 \mathrm{~h}$. The L-band data were, however, successfully employed to map the surface topography of the icefield with a $10 \mathrm{~m}$ uncertainty in height, and measure ice velocity with a precision of $4 \mathrm{mmd}^{-1}$ or $1.4 \mathrm{ma}^{-1}$. The corresponding error in strain rates is $0.05 \mathrm{a}^{-1}$ at a $30 \mathrm{~m}$ horizontal spacing. The one-dimensional interferometric velocities were subsequently converted to horizontal displacements by assuming a flow direction and complemented by feature-tracking results near the calving front. The results provide a comprehensive view of the ice-flow dynamics of Glaciar San Rafael. The glacier has a core of rapid flow, $4.5 \mathrm{~km}$ in width and $3.5^{\circ}$ in average slope, surrounded by slowermoving ice, not by rock. Ice velocity is $2.6 \mathrm{~m} \mathrm{~d}^{1}$ or $0.95 \mathrm{~km} \mathrm{a}^{-1}$ near the equilibriumline altitude $(1200 \mathrm{~m})$, increasing rapidly before the glacier enters the narrower terminal valley, to reach $17.5 \mathrm{md}^{-1}$ or $6.4 \mathrm{~km} \mathrm{a}^{-1}$ at the calving front. Strain rates are dominated by lateral shearing at the glacier margins $\left(0.4-0.7 \mathrm{a}^{-1}\right)$, except for the terminal-valley section, where longitudinal strain rates average close to $1 \mathrm{a}^{-1}$. This spectacular longitudinal increase in ice velocity in the last few kilometers may be a fundamental feature of tidewater glaciers.
\end{abstract}

\section{INTRODUCTION}

The Patagonian Icefields, divided into the northern and southern icefields, are amongst the largest mid-latitude ice masses, accounting for over $60 \%$ of the Southern Hemisphere's glacial area outside of Antarctica. This area is deemed essential for understanding global glacier response to climate change and hemispheric synchronicity but its glaciological characteristics are poorly known, mostly the result of inhospitable weather and inaccessibility of the outlet glaciers (Warren and Sugden, 1993).

In October 1994, NASA's Spaceborne Imaging Radar-C (SIR-C), on board the U.S. space shuttle Endeavour, collected radar interferometry data over both the northern (Hielo Patagónico Norte; HPN) and southern icefields (Hielo Patagónico Sur). Here, we present the results obtained for the northwestern flank of HPN, Chile (Fig. 1). These data include Glaciar San Rafael, the lowest-latitude tidewater glacier in the world and the most active glacier of HPN (Naruse, 1985; Warren, 1993). Four consecutive interferometric passes were collected in this area at both $\mathrm{C}-(\lambda=5.67 \mathrm{~cm})$ and L-band $(24.23 \mathrm{~cm})$ frequencies, with vertical transmit and receive polarization, at an exact repeat-pass time interval of $23.618 \mathrm{~min}$.
In an optimum configuration, SAR interferometry is capable of achieving meter-scale precision in topographic height (e.g. Rodriguez and Martin, 1992). With SIR-C, the performance of topographic mapping was expected to be lower for several reasons. One reason is the overwhelming accuracy with which the shuttle repeated its orbits, yielding very short interferometric baselines the distance separating the successive positions of the antennas when imaging the same point on the ground), which is appropriate for detecting surface changes but limits the achievable precision of topographic mapping. Topographic mapping was also affected by temporal changes in the scattering properties of the glacier surface and time-varying atmospheric delays which introduced additional noise sources in the data. These errors would have been eliminated if the satellite had operated two antennas simultaneously instead of a single antenna repeatedly (Goldstein, 1995). Finally, the interferometric baselines had to be estimated from the data, because the shuttle ephemeris were not sufficiently accurate, thereby introducing an additional error source.

In contrast, the repeat-pass SIR-C data were excellent for detecting surface changes because the short baselines minimized the need to have a fine description of surface topography and the use of short repeat-pass cycles 


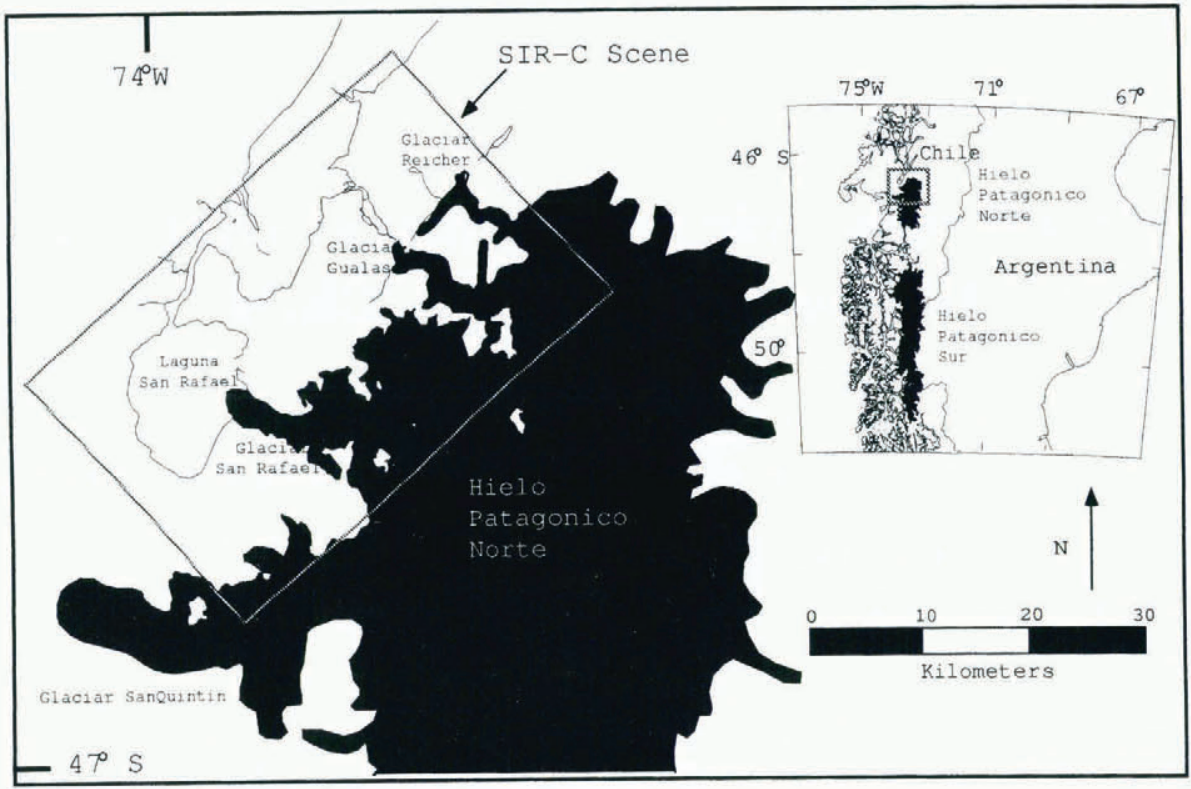

Fig. 1. Location map of the study area with inset showing the location of Glaciar San Rafael, Chile.

minimized the effect of surface changes on the temporal stability of the signal. These data were also the first radarinterferometry observations of the Patagonia Icefields, providing millions of measurement points for topography and velocity in a poorly known area and offering a unique opportunity to compare the merits and values of two radar frequencies for repeat-pass interferometry applications over icy terrain, in a temperate, dynamic and contrasted glaciological setting.

\section{STUDY AREA}

A false-color composite image of the study area is shown in Figure 2. The scene is centered at $46.55^{\circ} \mathrm{S}, 73.67^{\circ} \mathrm{W}$ and is 50 by $30 \mathrm{~km}$ in size. North is $47.7^{\circ}$ to the right of the top of the scene. SIR-C is flying from left to right, looking to its right perpendicular to its flight track and illuminating from the top at an angle $\theta_{z}=49^{\circ}$ below horizontal. Spatial resolution is $R_{r}=8.6 \mathrm{~m}$ in range (cross-track direction) on the ground and $R_{z}=8.2 \mathrm{~m}$ in azimuth (along-track direction). During generation of the interferometric products, we spatially averaged the data using six samples in range and six samples in azimuth, degrading spatial resolution to about $50 \mathrm{~m}$. Pixel spacing - about half the spatial resolution - was $31 \mathrm{~m}$ in the reduced data in both range and azimuth. Similar data were acquired on 8,9,10 and 11 October during orbits $125,141,157$ and 173 of the space shuttle, respectively, at night, about $1 \mathrm{~h}$ before midnight.

The SIR-C scene comprises the lower $25 \mathrm{~km}$ of Glaciar San Rafael, the only glacier of HPN that reaches the sea. As detailed by Aniya (1988), the glacier has a total area of $760 \mathrm{~km}^{2}$, with an accumulation area of $585 \mathrm{~km}^{2}$, the largest $(23 \%)$ of HPN. The glacier arises high up on the steep slopes of Monte San Valentin (3910 m), the highest peak of HPN, and flows for $46.4 \mathrm{~km}$ down the steep slopes of the western Andean walls before calving into Laguna
San Rafael, a tidal lagoon connected to the open fjord Golfo Elefantes to the north via a narrow channel, Rio Tempanos. Calving activity at the glacier front is spectacular and continuous (Warren and others, 1995). Ice velocity reaches $17-22 \mathrm{~m} \mathrm{~d}^{-1}$ at the glacier front (Kondo and Yamada, 1988), making Glaciar San Rafael one of the world's fastest non-surging glaciers. Rapid glacial flow is presumably sustained by very high precipitation, possibly reaching $10000 \mathrm{~mm}$ on the central part of the icefield (Fujiyoshi and others, 1987), pronounced topographic relief on the tectonically active western Andean margin (Reed and others, 1988) and warm ice temperatures, averaging $0^{\circ} \mathrm{C}$ throughout the year and causing high rates of ice deformation (Naruse, 1985).

\section{METHODS}

The principles of SAR interferometry have been described by Zebker and Goldstein (1986), Goldstein and others (1988), Gabriel and others (1989) and Zebker and others (1994). Gabriel and others (1989) demonstrated how to separate surface changes from surface topography using a simple geometric transformation. Zebker and others (1994) demonstrated how double-difference interferometry could be used to retrieve both surface topography and surface changes. The first example of the application of radar interferometry to glacier studies was given by Goldstein and others (1993). Other demonstrations of application were presented in subsequent years for Greenland (Fahnestock and others, 1994; Jezek and Rignot, 1994; Joughin and others, 1994; Kwok and Fahnestock, 1994; Rignot and others, 1994; Joughin, 1995), Alaska (Fatland and Lingle, 1994), Antarctica (Hartl and others, 1994) and Patagonia (Rignot and others, 1995a); and some have been published in the open literature (Joughin and others, 1995; Rignot and others, 
Rignot and others: Interferometric radar observations of Glaciar San Rafael, Chile

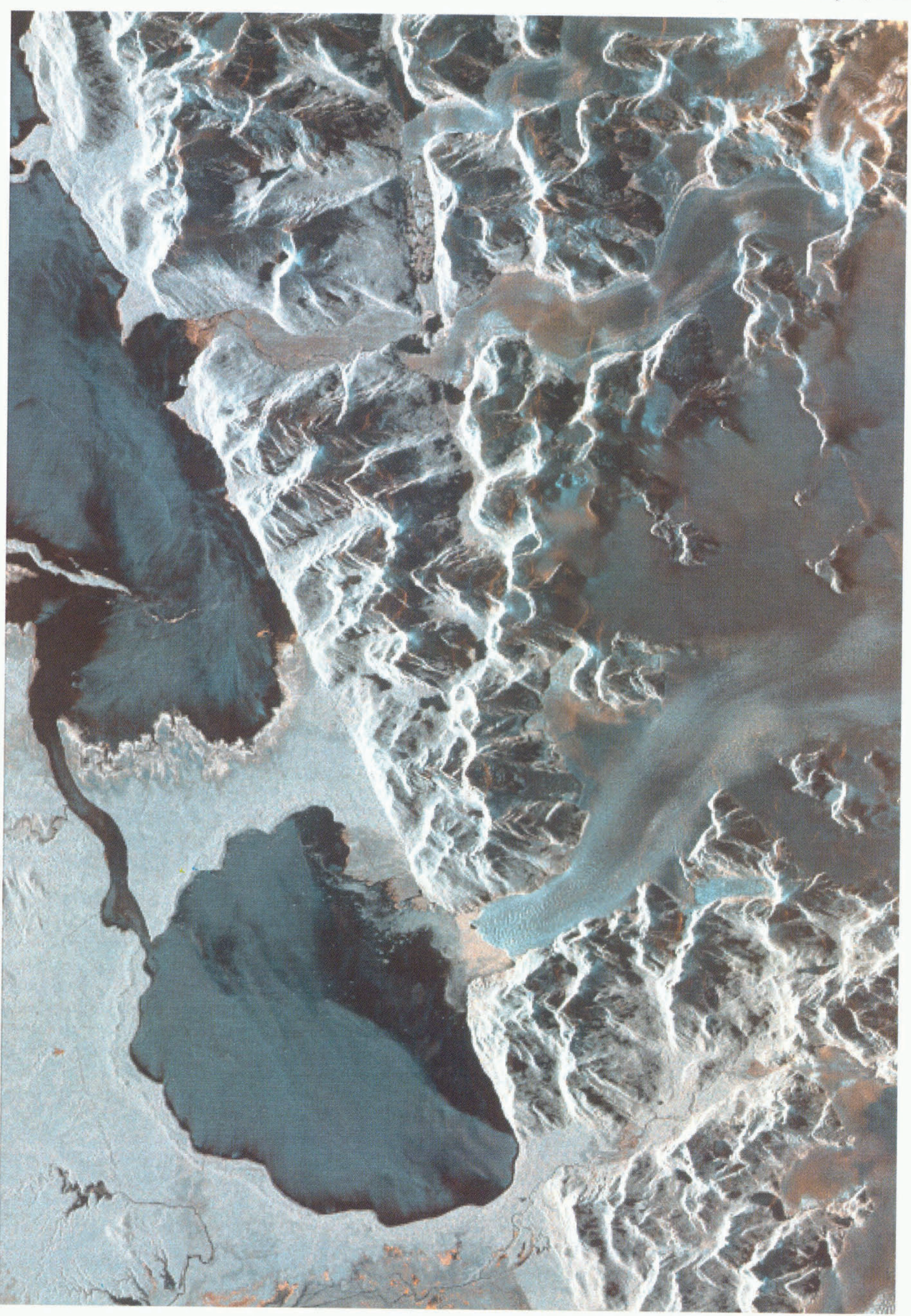

Fig. 2. False-color composite image of Glaciar San Rafael acquired by SIR-C SAR on 10 October 1994. C-band is red, Cband $+L$-band is green and L-band is blue. 
1995b; Joughin and others, 1996; Kwok and Fahnestock, 1996; Rignot and others, 1996).

SAR interferometry exploits the coherence of the SAR signal measured by two slightly displaced radar antennas to measure wavelength-sized displacements in the position of the scattering centers which back-scatter the radar illumination. These millimetric displacements result from the combined effects of the slight offset in position of the two antennas, the topographic height of the scattering centers and the motion of the scatterers.

With one pair of SAR images collected with two antennas simultaneously, the surface-topographic profile may be retrieved from the phase of the SAR signal, knowing the SAR-imaging geometry (Zebker and Goldstein, 1986). When the SAR images are acquired at different instances, both surface deformation and surface topography affect the phase values (Gabriel and others, 1989). If a digital elevation model of the area is available, only one image pair is needed to measure surface deformation. If surface topography is unknown, two image pairs are needed to estimate both topography and surface motion (Zebker and others, 1994).

To form a SAR interferogram, the SAR images must be precisely registered and cross-correlated, the phase values must be unwrapped and absolutely referenced, and the interferometric base lines must be estimated and removed from the interferograms (Zebker and Goldstein, 1986).

A standard technique for estimating the image offsets is to locate the correlation peak of the signal intensity between the two images at several locations and interpolate the results in between, for instance, using plane-fitting (e.g. Goldstein and others, 1993). Although this registration technique works for most glaciers, it was not sufficient for Glaciar San Rafael, where ice blocks translate by as much as 1.5 pixel $^{-1}$ in the lower reaches. We therefore included additional offsets along the glacier direction, complicating the registration process but resulting in a significant increase in phase coherence over fast-moving ice.

For phase unwrapping, we used the technique of Goldstein and others (1988) after filtering the data with a two-dimensional spectral filter developed by C. L. Werner (unpublished information, 1994) which reduced phase noise while preserving interferometric details.

To estimate the baseline, we selected 51 tie points from a published Chilean map at a 1:50000 scale over rock areas (the map gives no elevation data over the glacier). The results are a baseline of $B_{21}=326.9 \mathrm{~m}$ (see Appendix for notations) increasing by $0.55 \mathrm{~m}$ alongtrack, with a baseline angle $\alpha_{21}=-41.6^{\circ}$ decreasing by $0.08^{\circ}$ along-track for the orbit pair 157-173. For the second orbit pair 157-141, the baseline was $B_{23}=47.8 \mathrm{~m}$, increasing by $0.14 \mathrm{~m}$ along-track and $\alpha_{23}=-4.5^{\circ}$ decreasing by $0.39^{\circ}$ along-track. The perpendicular baselines, $B_{\perp}$ (Appendix), were respectively 43.6 and $33.7 \mathrm{~m}$ for the two image pairs. Ice motion and topography were separated using the earthflattening technique of Zebker and others (1994). Surface elevation and ice motion were subsequently resampled to ground-range geometry prior to the calculation of strain rates (Appendix). The interferometric products are shown in Figures 3-5.

\section{INTERFEROMETRIG PRODUCTS}

In this section, we discuss the precision and physical interpretation of three interferometric products:

(1) phase coherence, (2) ice motion and (3) surface topography.

\section{Phase coherence}

Phase coherence is a relevant interferometric product because it provides discriminative information on the type of surface being imaged, independent of its radar brightness. It also provides information on the spatial distribution of phase noise in the $\mathrm{SAR}$ interferograms.

The phase-coherence images of the orbit pair 157173 are shown in Figure 3 at $\mathrm{C}$ and L bands. Phase coherence, $\rho$, is low at $\mathrm{C}$ band, especially on the glacier $(\rho<0.4)$. It is higher on the outwash plains surrounding Laguna San Rafael. The largest coherence ( $\rho=0.7-0.8$ ) is recorded along the bare sides of the terminal valley of Glaciar San Rafael occupied by the glacier before its recent retreat, and over mountain tops denuded of vegetation (personal visit, 1995). Coherence is large $(\rho=0.7)$ on the marsh bordering the northern side of the peninsula north of Laguna San Rafael (personal visit, 1995). Elsewhere in the plains, where a mature temporal rain forest develops, coherence is lower $(\rho=0.4-0.6)$. Low coherence is expected with C-band repeat-pass imagery over forest, because volume-scattering from the upper canopy dominates the signal and wind randomly agitates the scatterers (branches, twigs and foliage of the upper canopy), modifying their spatial distribution from one instant to the next. Over flooded areas (marsh), stronger scattering from double reflections on the wet ground and tree-trunks helps maintain a higher temporal stability of the signal, independent of changes in volume-scattering. Overall, signal coherence is high enough for topographic mapping of the outwash plains but not for most of the glacier, except perhaps for a few high-elevation areas.

At $\mathrm{L}$ band, phase coherence is high $(\rho>0.95)$ at low elevations over the forest and over the slow-moving part of the icefield $(\rho=0.75)$, intermediate over fast-moving ice $(\rho=0.55)$, moderate $(\rho=0.35)$ in areas of high shear-strain and low $(\rho<0.2)$ over radar-dark areas such as open water and shadowed regions. Outside the icefield, coherence decreases above a certain altitude which coincides with both the snow line and the limit of vegetation. Snow-covered areas are less well correlated than vegetated areas. A sharp contrast in phase coherence exists between glacier ice and rock across the entire icefield, because rocks are more coherent than glacier ice. In shadowed regions, the contrast is reversed. The ice margin is nevertheless more distinct in the coherence image than it is in the radar-amplitude data (Fig. 2) or in optical photographs (Rignot and others, 1996).

We quantitatively examined the factors that could potentially reduce phase coherence. These factors are divided into two categories: (1) system effects and (2 surface effects. Surface effects are difficult to track analytically. They correspond to changes in the nature 
a

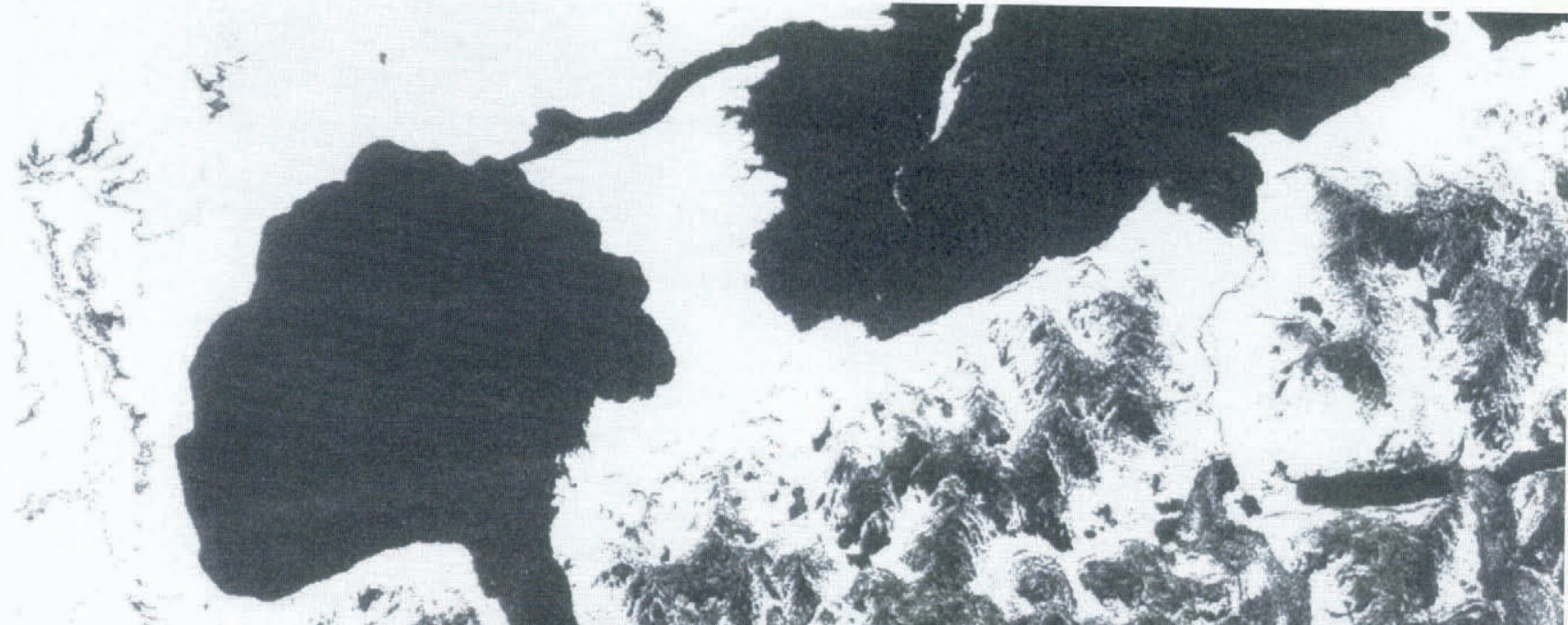

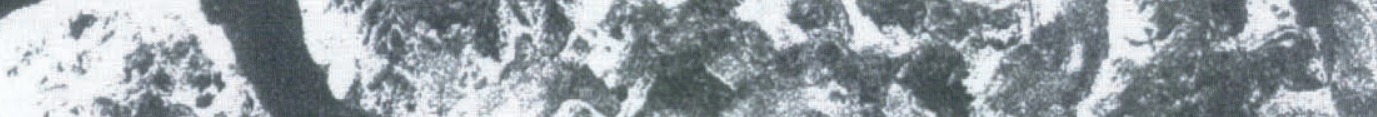

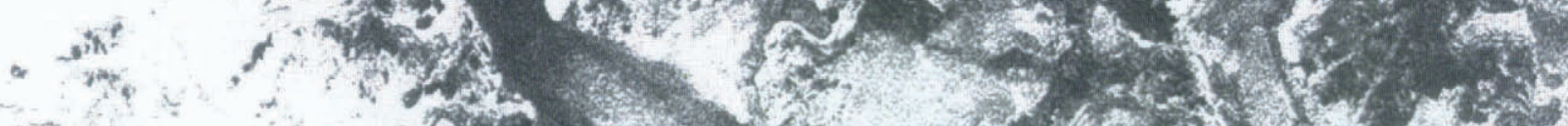

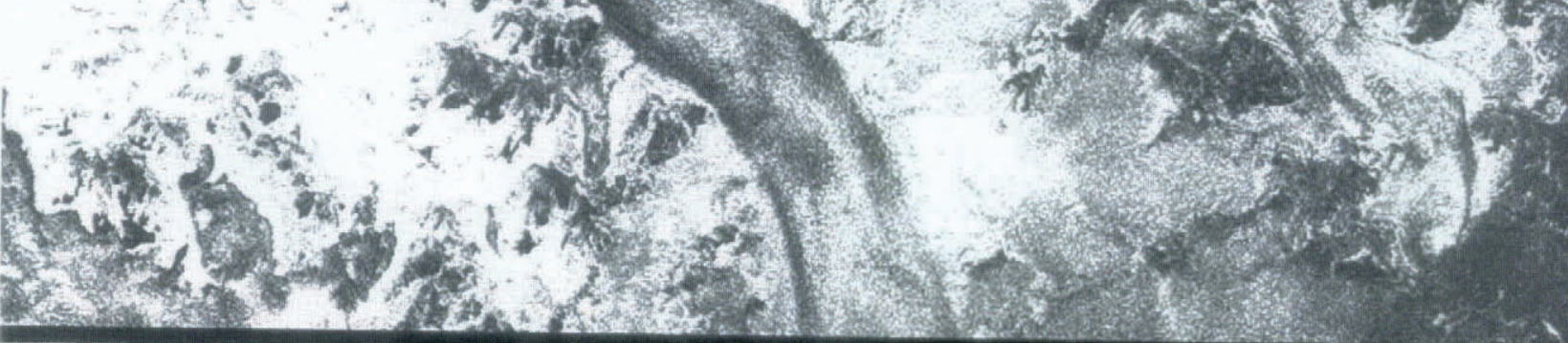

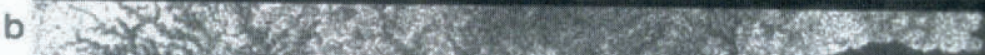
(3)

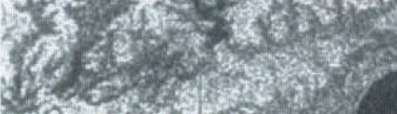

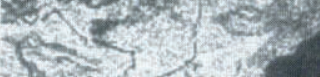

(1)

bectiog.

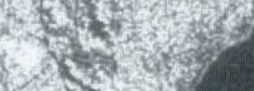

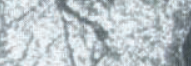

2. 1.20

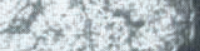

Fis.

30 inters

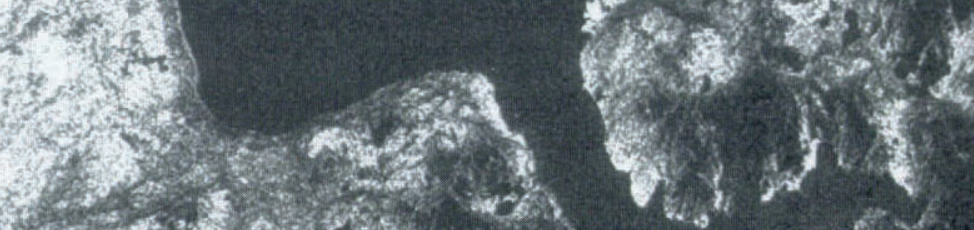

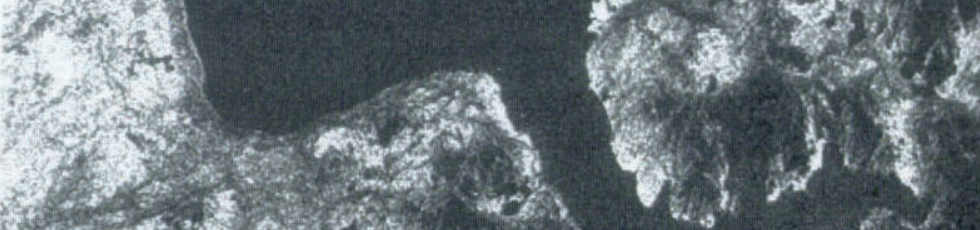

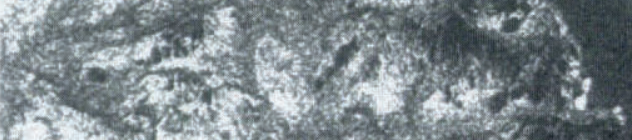

8.

1.
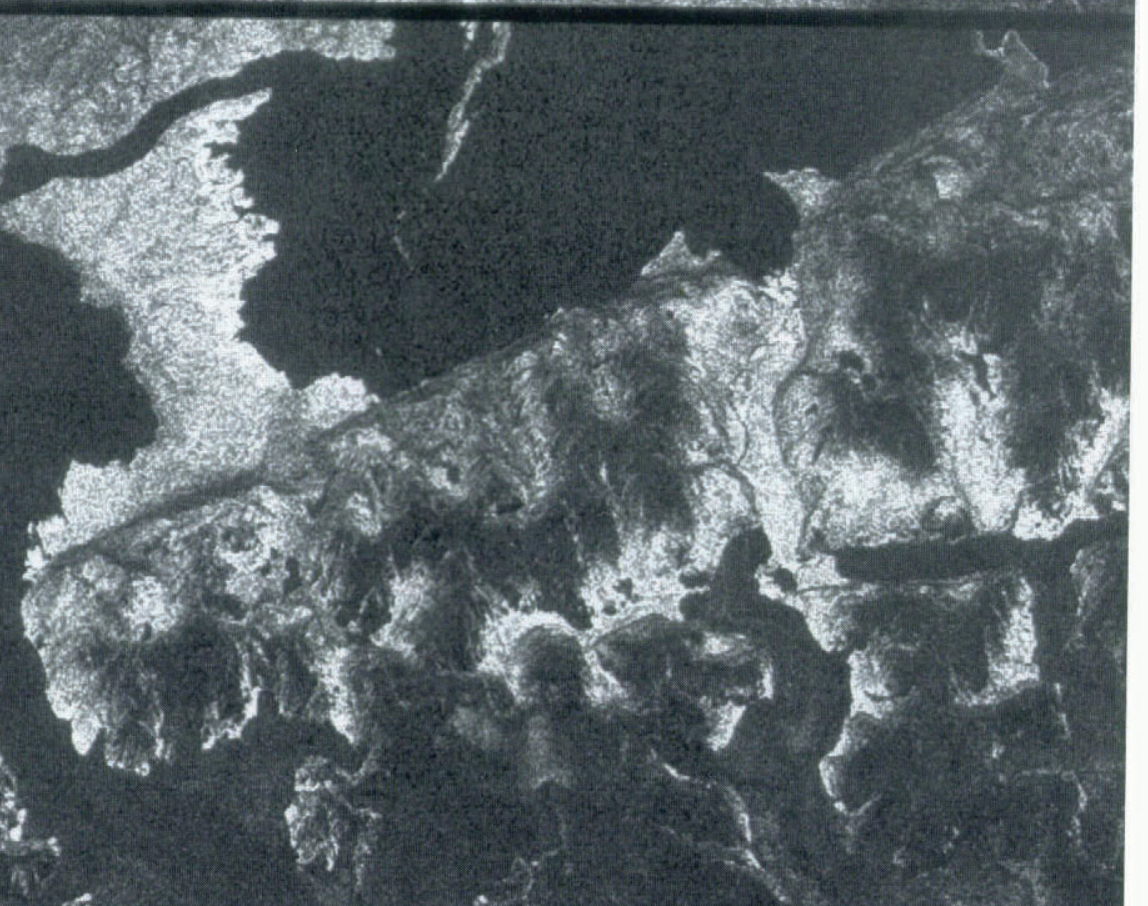


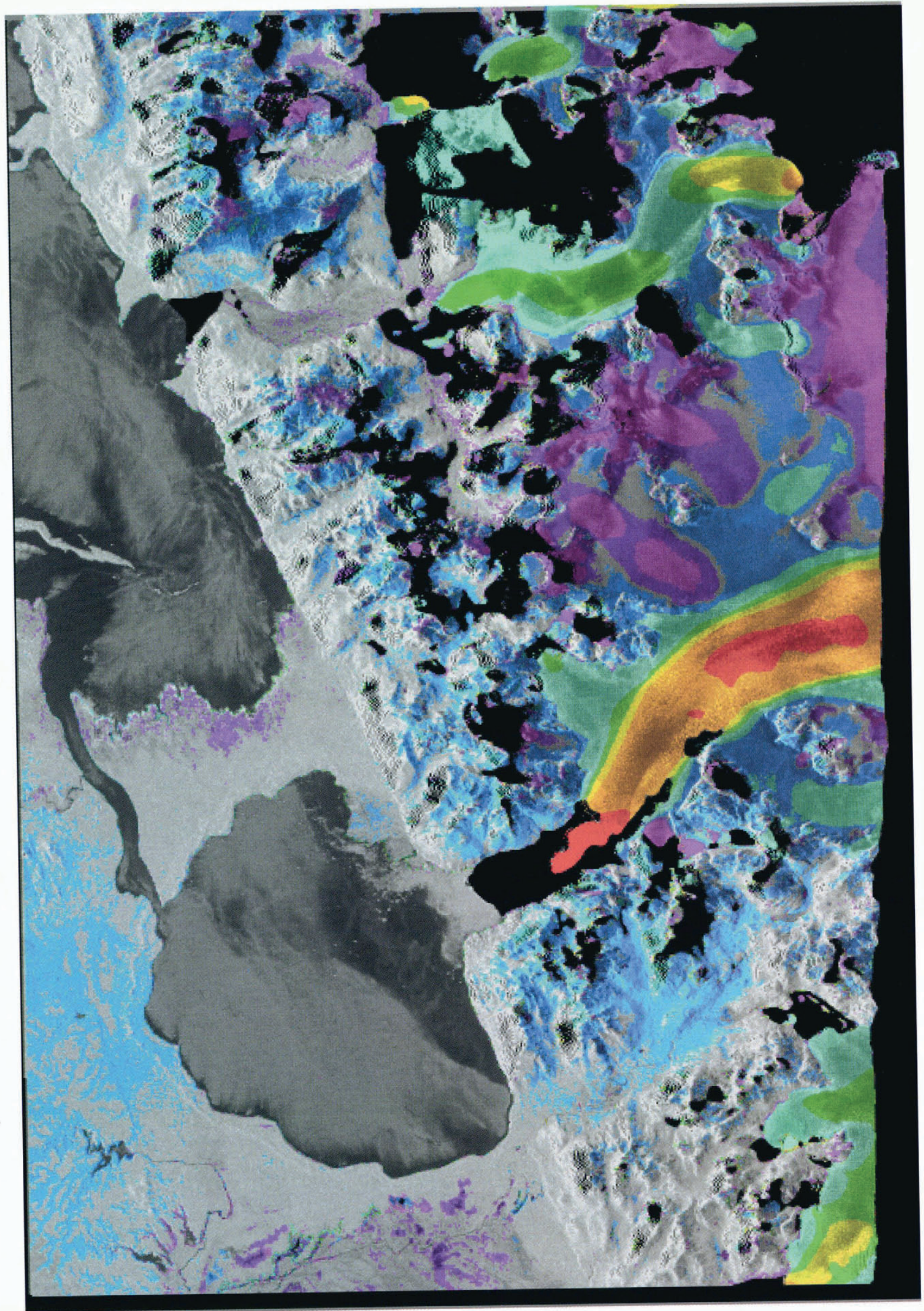

Fig. 4. Color-composite image of the surface topography of Glaciar San Rafael, Chile, in ground-range geometry. Hue and saturation are proportional to the inverse of height and intensity is proportional to radar brightness. No radar information is available in black areas. 


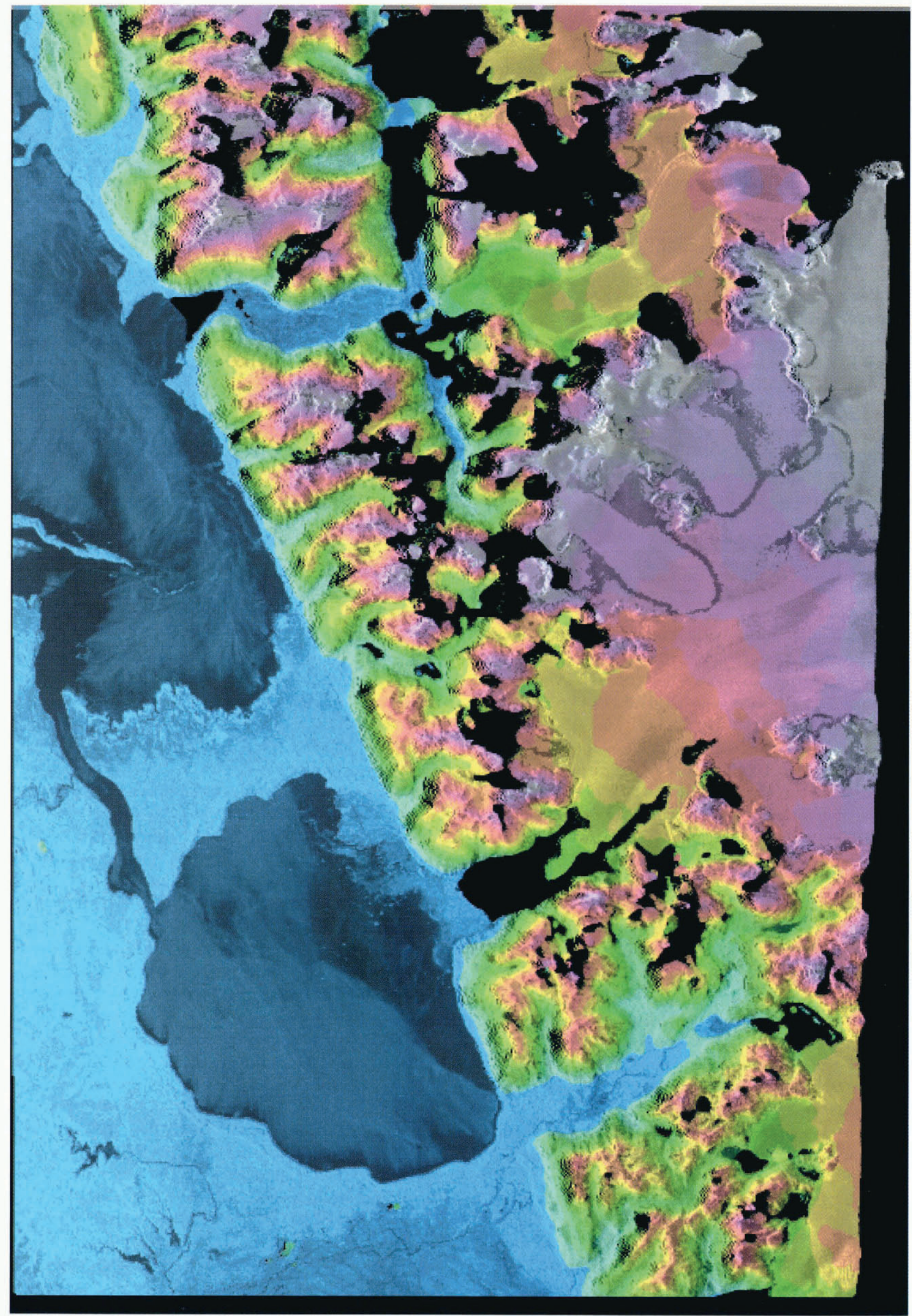

Fig. 5. Color-composite image of ice motion in the direction of the radar illumination. Ice velocity is light purple $(<-3 \mathrm{~cm}$ $\left.d^{-1}\right)$, purple $\left(-3\right.$ to $\left.-0.5 \mathrm{~cm} \mathrm{~d}^{-1}\right)$, grey $\left(-0.5\right.$ to $\left.+0.5 \mathrm{~cm} \mathrm{~d}^{-1}\right)$, blue $\left(0.5\right.$ to $\left.3 \mathrm{~cm} \mathrm{~d}^{-1}\right)$, light blue $\left(3-20 \mathrm{~cm} \mathrm{~d}^{-1}\right)$, green $\left(20-45 \mathrm{~cm} \mathrm{~d}^{-1}\right)$, yellow $\left(45-85 \mathrm{~cm} \mathrm{~d}^{-1}\right)$, orange $\left(85-180 \mathrm{~cm} \mathrm{~d}^{-1}\right)$, and red $\left(>180 \mathrm{~cm} \mathrm{~d}^{-1}\right)$. Color saturation is modulated by radar brightness. 
and/or spatial distribution of the scatterers, either due to motion of the surface or changes in its electrical and structural properties. System effects include: (1) thermal noise, and (2) geometric decorrelation. Each system effect acts as an independent noise source, thereby reducing phase coherence through a set of multiplicative coherence coefficients.

The coherence coefficient for thermal noise $(\mathrm{Li}$ and Goldstein, 1990) is

$$
\rho_{\mathrm{SNR}}=\left(1+\mathrm{SNR}^{-1}\right)^{-1}
$$

where SNR is the signal-to-noise ratio. We estimated system noise by measuring the back-scatter response of the darkest parts of the radar scene, meaning calm open water and shadowed regions. The SNR of glacier ice was deduced to be $>24 \mathrm{~dB}$ at both $\mathrm{L}$ and $\mathrm{C}$ band, meaning $\rho_{\mathrm{SNR}}>0.99$. Hence, thermal noise did not significantly reduce phase coherence on glacier ice.

The coherence coefficient modeling the geometric decorrelation from the base-line separation between two antennas is ( $\mathrm{Li}$ and Goldstein, 1990)

$$
\rho_{\mathrm{B}}=1-\frac{2 B_{\perp} R_{r} \sin ^{2}\left(\theta_{z}\right)}{\lambda R} .
$$

$B_{\perp}$ is the perpendicular base line (Appendix), $\theta_{z}$ is the radar-illumination angle with the horizontal, $z$ is the surface elevation and $R$ is the range distance from the radar antenna to the illuminated surface. With $B_{\perp}=77 \mathrm{~m}$, $R_{r}=50 \mathrm{~m}$ and center-scene values $\theta_{z}=49.1^{\circ}$ and $R=288 \mathrm{~km}$, we calculated $\rho_{B}=0.99$ at $\mathrm{L}$ band and $0.96 \mathrm{C}$ band, meaning a reduction in coherence of less than $4 \%$.

Geometric decorrelation also arises from changes in squint angle of the radar antenna, which is the angle of the radar illumination with the plane perpendicular to the flight track. This angle is usually near zero but changes slightly from one flight to the next. As a result, the azimuth spectrum of the SAR signal is shifted by variable amounts on different dates. This phasecoherence reduction was not discussed by $\mathrm{Li}$ and Goldstein (1990). If we model the azimuth-impulse response as a $\sin (x) /(x)$ function, the azimuth SAR spectrum is a rectangle of width $B W$ (the Doppler bandwidth), centered at a Doppler frequency $f_{\mathrm{d}}$ $=\left(2 V_{\mathrm{s}} \sin (\psi) / \lambda\right)$, where $\psi$ is the squint angle and $V_{\mathrm{s}}$ is the radar-platform velocity (Curlander and McDonough, 1991). The coherence coefficient due to a change $\Delta \psi$ in squint angle between two passes is deduced from the degree of overlap between the twoazimuth spectra

$$
\rho_{\psi}=1-\frac{2 V_{\mathrm{s}} \Delta \psi}{\lambda B W} .
$$

Here, $B W$ was $950 \mathrm{~Hz}$. The Doppler frequencies images 141,157 and 173 were precisely estimated during SAR processing as, respectively, $f_{\mathrm{d}}=-680,-584$ and $-218 \mathrm{~Hz}$ at $\mathrm{C}$ band and values 4.27 times smaller (wavelength ratio) at L band. From Equation (3), signal coherence was reduced by $10 \%$ for pair $141-157$ and $38 \%$ for pair $157-173$ at $\mathrm{C}$ band but only $2-9 \%$ at $\mathrm{L}$ band.

In conclusion, system effects reduced phase coherence by only a few per cent and do not explain the large difference in coherence between $\mathrm{L}$ and $\mathrm{C}$ band, which we therefore attribute to surface effects.

Surface ablation from melting and glacier wind is one surface effect which limits phase coherence, because it affects the scattering properties of the upper glacier surface. Surface ablation rates are high on Glaciar San Rafael, reaching $7 \mathrm{cmd}^{1}$ in the summer at sea level (Kondo and Yamada, 1988). L-band signals are expected to be less sensitive to surface changes, because they penetrate deeper into the snow/firn and ice than C-band signals and are scattered by larger-sized dielectric heterogeneities at and below the surface.

We calculated the expected penetration depths of Land C-band signals over various parts of the glacier. In the accumulation area of Glaciar San Rafael, the snowwater content decreases from 8 to $4 \%$ from the surface down to $19.7 \mathrm{~m}$ depth (Yamada, 1987). Using the dielectric mixing formula of Mätzler (1987, equation (2.32), p. 300) with a dielectric constant of 1.97 for dry snow (Matzler, 1987, equation (2.19), p. 282) and a snow density of $500 \mathrm{~kg} \mathrm{~m}^{-3}$ (Yamada, 1987), we calculated a penetration depth, $d_{\mathrm{p}}$, of $20 \mathrm{~cm}$ at $\mathrm{C}$ band and $30 \mathrm{~cm}$ at $\mathrm{L}$ band. Perhaps the $10 \mathrm{~cm}$ increase in penetration depth at $\mathrm{L}$ band is sufficient to change signal coherence dramatically. Over bare ice, $d_{\mathrm{p}}$ is larger. Using an imaginary part of the dielectric constant of 0.0013 at $\mathrm{L}$ band and 0.0018 at $\mathrm{C}$ band for glacier ice at $-1^{\circ} \mathrm{C}$ (Evans, 1965), we obtained $d_{\mathrm{p}}=9 \mathrm{~m}$ at $\mathrm{C}$ band and $53 \mathrm{~m}$ at $\mathrm{L}$ band. These calculations overestimate $d_{\mathrm{p}}$, because they neglect ice impurities and surface melt but they illustrate the greater penetrability of L-band signals into bare ice and, as a result, its likeliness to be less sensitive to surface changes.

Rotations of ice blocks under high lateral shear also reduce phase coherence, because the aspect angle of the scatterers changes differently within each resolution element. Using the theoretical model proposed by Zebker and Villasenor (1992), we found coherence should be destroyed after a rotation of $1.2^{\circ}$ at $\mathrm{L}$ band and $0.3^{\circ}$ at $\mathrm{C}$ band in the SIR-C data. Spatial resolution and repeat-pass time interval further limit the detection of strain rates. When ice blocks move by $>\lambda / 2$ from one resolution cell to the next, phase cycles are no longer detectable and phase unwrapping is impossible. The corresponding limit in detectable strain rate is $0.014 \mathrm{~d}^{-1}$ or $5.2 \mathrm{a}^{-1}$ at $\mathrm{L}$ band and $0.003 \mathrm{~d}^{-1}$ or $1.2 \mathrm{a}^{-1}$ at $\mathrm{C}$ band. Phase coherence is hence more significantly reduced at the higher frequencies. The shear margins of Glaciar San Rafael and the section of rapid flow in the terminal valley are example areas where these limitations strongly apply at $\mathrm{C}$ band, not at $\mathrm{L}$ band. One exception is the last $2 \mathrm{~km}$ segment of glacial flow for which even the L-band signals decorrelate. There, melting and deformation are, however, so severe a repeat-pass cycle of only a few hours would have been necessary to maintain high signal coherence.

In conclusion, the phase-coherence images illustrate radar signals are more stable at the longer wavelengths over glacial terrain and provide much better chances of successful repeat-track SAR interferometry, along with the possibility to monitor larger strain rates, possibly at greater depths and to delineate the ice margin better. 


\section{Ice motion}

The precision of the velocity estimates obtained from the SIR-C data is influenced by a variety of factors which include base-line uncertainties, phase noise and unknown range delays caused by system clock-timing, datasampling clock jitter and atmospheric delays. is

Rodriguez and Martin (1992) showed phase noise, $\sigma_{\phi}$,

$$
\sigma_{\phi}=\frac{1}{\sqrt{N}} \frac{\sqrt{1-\rho}}{\rho}
$$

where $N$ is the number of looks at the data. With $N=36$ and $\rho=0.35$ (shear zones), 0.55 (fast ice) and 0.75 (slowmoving ice), we find $\sigma_{\phi}=0.38,0.20$ and 0.11 . The corresponding uncertainty in velocity, $\sigma_{v}=(\lambda / 4 \pi) \sigma_{v}$, is, respectively, 2.1, 3.9 and $7.4 \mathrm{~mm} \mathrm{~d}^{-1}$, which means about $4 \mathrm{~mm} \mathrm{~d}^{-1}$ on average.

Other error sources are more difficult to quantify. Their combined effect is illustrated in Figure 5, where apparent surface motion is also revealed over ice-free terrain yet with a much lower amplitude than on the glacier. The largest errors occur at high elevation and form kilometer-sized features. These errors are, however, weakly correlated with topography, which suggests they are not due to residual baseline uncertainties. We attribute them to unknown range delays associated with atmospheric perturbations. At low elevation, where terrain is nearly level and baseline effects are definitely ruled out, the signal $\mathrm{rms}$ is $3 \mathrm{~mm}$ of motion. The peak-topeak signal is about $-5 \mathrm{~mm}$ to $+5 \mathrm{~mm}$. Similar atmospheric delays were recorded in the California desert and attributed to turbulent mixing of water vapor Goldstein, 1995), because they were the same at both L- and Cband frequency. In this study, atmospheric delays introduced a $3 \mathrm{~mm} \mathrm{~d}^{-1}$ error source in the velocity data, increasing the overall velocity noise to about $5 \mathrm{~mm} \mathrm{~d}^{-1}$. Because they spread over the scale of several kilometers, however, atmospheric delays do not affect the precision of strain rates, which is solely limited by phase noise.

Strain rates are directly obtained from the interferometric velocities. Computed over a double-grid spacing, their uncertainty is $0.05 \mathrm{a}^{-1}$. Gradients in strain rates (needed to calculate stresses) computed over three grid points with double-grid spacing have an error of $0.0015 \mathrm{a}^{-1}$ $\mathrm{m}^{-1}$. Increasing the grid spacing to $150 \mathrm{~m}$ would accordingly decrease these errors by a factor of 5 for strain rates and 25 for strain-rate gradients.

The interferometric velocities shown in Figure 5 provide only one component of horizontal motion. To get a full three-dimensional velocity, two additional interferometric pairs acquired at two different track angles are necessary. In practice, interferograms from perpendicular passes are rarely acquired and obtaining three different tracks is unheard of even with airborne systems. To constrain the velocity vector based on one measured component of the velocity, we therefore assumed (1) ice flows parallel to the ice surface, and (2) horizontal flow direction is known. Because glacier thinning $\left(<2.7 \mathrm{~cm} \mathrm{~d}^{-1}\right)$ is much less than ice motion $\left(>250 \mathrm{~cm} \mathrm{~d}^{-1}\right)$, the first assumption is reasonable, as for most glaciers. Flow direction is more difficult to guess. In
Greenland, over areas containing small bumps and hollows in surface topography, Rignot and others (1995b) showed pairs of concentric circles appearing in the SAR interferograms are aligned with flow direction. This technique may not work in the slower-moving vast interior of the ice sheet, where surface topography is more subdued and was also not useful for Glaciar San Rafael. Instead, we guessed the flow direction from the glacier flowlines, the geometry of the shear margins and the proximity of valley walls. Knowing flow direction, the local incidence angle of the radar illumination (computed from the SAR imaging geometry and the digital elevation model of the glacier) and surface slope, the interferometric displacements were converted into horizontal displacements (Appendix). Strain rates were deduced from central differencing along longitudinal and transverse axis (Appendix).

\section{Surface topography}

Height errors are caused by unknown range delays, improper knowledge of the base line, altitude and attitude of the spacecraft, and phase noise. Li and Goldstein (1990) expressed the error caused by phase noise as

$$
\sigma_{h}=\frac{\lambda R \cos \theta_{z}}{4 \pi B_{\perp}} \sigma_{\phi} .
$$

Here, $B_{\perp}$ is the sum of the perpendicular base lines from the two interferograms or $77 \mathrm{~m}$ (Appendix). Using Equation (5), we find $\sigma_{h}=47 \sigma_{\phi}$. From phase noise only, $\sigma_{h}$ is $5 \mathrm{~m}$ for slow-moving ice, $9 \mathrm{~m}$ for fast-moving ice and $18 \mathrm{~m}$ in the marginal shear zones, meaning about $10 \mathrm{~m}$ on average. Kilometer-sized atmospheric delays increase height errors to about $12 \mathrm{~m}$ on average.

These height errors are large and are not satisfactory for monitoring the glacier thickness using short time-series of interferometric passes. Glaciar San Rafael has been shown to be thinning at a rate $<10 \mathrm{~m} \mathrm{a}^{-1}$ in the $1980 \mathrm{~s}$ (Aniya, 1988). A several year time interval would be necessary to detect elevation change due to glacier thinning from the SIR-C data. As detailed earlier, the SIR-C mission was not designed to produce highaccuracy topographic maps. With a dedicated system operating two antennas simultaneously or operating one antenna with a large baseline, height errors would be easily decreased by one order of magnitude, atmospheric effects would automatically eliminate and meter-scale annual changes in surface elevation would become detectable.

\section{DISCUSSION}

The ice-motion map (Fig. 5) provides a comprehensive view of the ice-flow dynamics in the northwestern flank of HPN. Ice flows more rapidly along Glaciar San Rafael than any of the neighboring glaciers. Purple areas, corresponding to motion away from the radar, clearly show ice flowing from the interside ridges into the main stream of Glaciar San Rafael and reveal the division of the upper accumulation area into two drainage basins. The most striking feature is that, in contrast to its 
neighbors, Glaciars San Quintin, Reicher and Gualas, the center part of Glaciar San Rafael resembles that of an ice stream. There is a core of rapid flow along much of the length of the glacier that is surrounded by slower-moving ice, not by rock. This rapid ice current is also seen in the upper accumulation area of the glacier, not imaged by SIR-C SAR, but imaged in hand-held photographs of the central part of the icefield taken from the shuttle (Rignot and others, 1996). The core of rapid flow is $4.6 \mathrm{~km}$ in width, with a surface slope of $3.5^{\circ}$ and a velocity two orders of magnitude faster than the surrounding ice. Ice velocity along the center line (Fig. 6) is $2.6 \mathrm{~m} \mathrm{~d}^{-1}$ near the equilibrium-line altitude $(1200 \mathrm{~m})$, increasing to $>12 \mathrm{md}^{-1}$ in the glacier lower reaches where SAR interferometry breaks down. There, we estimated horizontal motion by tracking crevasses between registered pairs of SAR amplitude images, using a crosscorrelation technique similar to the one used to register the complex amplitude images. Although the measurement uncertainty is large $\left(1 \mathrm{~m} \mathrm{~d}^{-1}\right)$, the results complement and in one place overlap the SAR interferometry results. Ice velocity reaches $17.5 \mathrm{~m} \mathrm{~d}^{-1}$ or $6.4 \mathrm{~km} \mathrm{a}^{-1} 100 \mathrm{~m}$ from the calving front. This enormous velocity is consistent with earlier estimates by Naruse (1985) and Kondo and Yamada (1988).

Where ice velocity exceeds $12 \mathrm{md}^{-1}$, ice thickness is likely about $350 \mathrm{~m}(180 \mathrm{~m}$ at the front from Warren and others (1995) and $450 \mathrm{~m}$ calculated at the equilibrium line by Rignot and others (1996)). The component of ice velocity due to internal deformation, calculated using a flow-rate coefficient of $180 \mathrm{kPa}^{\frac{1}{3}}$, is only $0.5 \mathrm{~m} \mathrm{~d}^{-1}$, much smaller than the measured surface velocity. Glacier sliding is therefore predominant and the measured surface velocities essentially correspond to basal sliding velocities. A similar calculation performed at the equilibrium line indicates internal-deformation velocities of about $1.5 \mathrm{~m} \mathrm{~d}^{-1}$, lower than the observed surface velocity $\left(2.6 \mathrm{md}^{-1}\right)$ and suggesting much less basal sliding.
The effective strain-rate, $\dot{\epsilon}_{\mathrm{e}}$, (Fig. 7) is ten times smaller in the center of Glaciar San Rafael $\left(<0.1 \mathrm{a}^{-1}\right)$ than at the margins of the core of rapid flow where it is dominated by lateral shear. Ice softening probably occurs at the margins of the fast part of Glaciar San Rafael, decoupling the main stream from the rest of the glacier ice and helping the progression of rapid flow. Along the center line, $\dot{\epsilon}_{\mathrm{e}}$ is $0.15 \mathrm{a}^{-1}$ at $1200 \mathrm{~m}$ elevation,

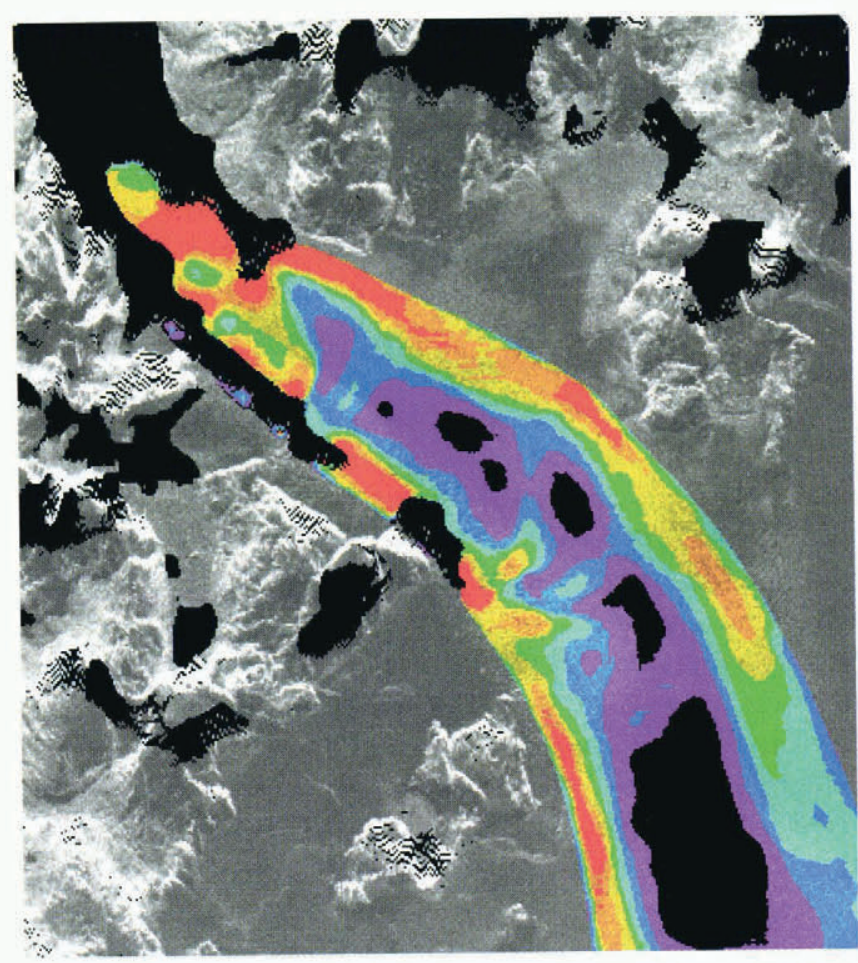

Fig. 7. Effective strain rate, $\dot{\epsilon}_{\mathrm{e}}$, at the surface of Glaciar San Rafael, modulated by radar brightness. Purple, blue, light blue, green, yellow, orange and red correspond respectively to $\dot{\epsilon}_{\mathrm{e}}>0.1,0.2,0.3,0.4,0.5,0.6$ and 0.7 . No strain rates were computed in the grey areas.

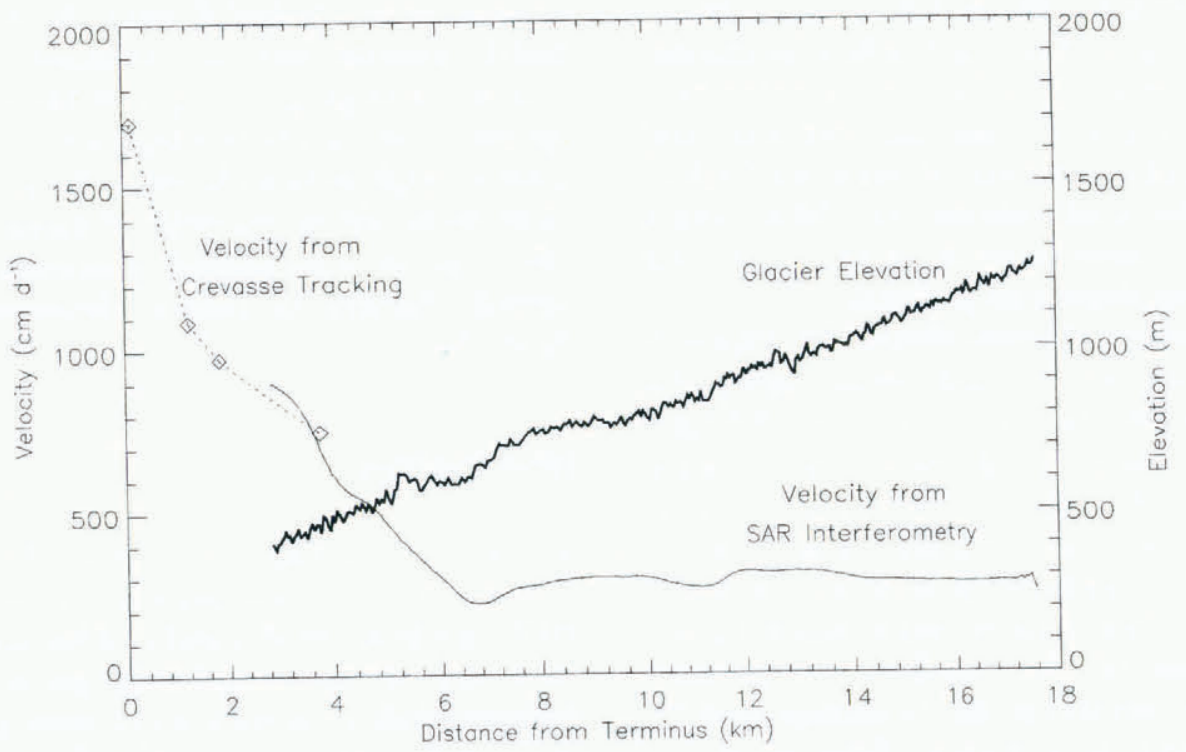

Fig 6. Horizontal ice velocity (continuous line) and surface elevation (dotted line) of Glaciar San Rafael obtained from $S A R$ interferometry along its center line versus the distance to the calving front. Complementary velocity estimates obtained from tracking of crevasses are shown with square symbols. 
increasing to about $1 \mathrm{a}^{-1}$ in the $2.5 \mathrm{~km}$ wide and $5 \mathrm{~km}$ long terminal valley. This large gradient is not due to lateral shear but to an increase in longitudinal stretching of the glacier near the terminal valley, where more rapid flow develops.

Naruse (1985) had previously measured an increase in speed from 13 to $17 \mathrm{~m} \mathrm{~d}^{-1}$ in the last kilometer of glacier flow, corresponding to a longitudinal strain of $1.5 \mathrm{a}^{-1}$, consistent although slightly higher than our crevassetracking results. The interferometry data reveal this phenomenon initiates about $6.4 \mathrm{~km}$ from the calving front, or $1 \mathrm{~km}$ prior to glacier narrowing in the terminal valley. Ice thickness, bed geometry and basal conditions are not known for this glacier. We may suspect that, as for other tidewater glaciers, its spectacular speed-up is caused by enhanced basal sliding due to high glacial water pressure and is sustained by the large longitudinal stress gradients caused by the release of back-pressure due to ice loss at the glacier front (Meier and Post, 1987).

Subglacial water is abundant at Glaciar San Rafael. Precipitation is high $\left(4000 \mathrm{~mm} \mathrm{a}^{-1}\right.$ at sea level $)$ and melt rates are high. In the last $6 \mathrm{~km}$, the glacier is a chaos of crevasses and seracs. Severe crevassing could easily triple the surface area of the glacier and enhance meltwater production to about $1 \mathrm{~km}^{3} \mathrm{a}^{-1}$ in the last $5 \mathrm{~km}$. This meltwater may reach the glacier bed to increase basal sliding or refreeze in crevasses to enhance creep rates through ice softening. Additional water input is also provided by numerous river streams which flow from the steep slopes of the interside mountain ridges (personal visit, 1995). At the glacier front, outflow of glacial water is manifest by the presence of large (tens of meters) circular cavities within the lower part of the calving face, strong and persistent turbulent upwelling of water near the northern margin (Warren and others, 1995) and rapid motion of brash ice and icebergs away from the glacier front. A high water input should decrease the effective water pressure at the bed and enhance basal sliding and flow speed (Meier and Post, 1987). The increase in flow speed of Glaciar San Rafael is very abrupt and could probably be localized across the entire glacier width, within a few hundred meters. Its shape and location must be strongly influenced by the particular bed geometry of the glacier at that location or correspond to an area of confluence of subglacier water from various directions.

Few longitudinal velocity profiles of tidewater glaciers are available for comparison with the data acquired on Glaciar San Rafael. Krimmel's (1992, fig. 10, p. 14) observations of Columbia Glacier, Alaska, however, show an abrupt and steady increase in velocity from about 3 to $>10 \mathrm{md}^{-1}$ within $6 \mathrm{~km}$ of the calving face, in large contrast to the flow pattern exhibited by the glacier at higher elevations. The rate of longitudinal stretching of Columbia Glacier is smaller than that recorded on Glaciar San Rafael but the flow pattern is strikingly similar. A pronounced longitudinal stretching of glacier ice in the terminal section of a glacier may therefore be a fundamental feature of tidewater glaciers. The location of the zone of longitudinal stretching could be a characteristic of the stability and thickness regime of the glacier, somewhat comparable to the grounding line of floating glaciers.

\section{CONGLUSIONS}

We retrieved both the surface topography and ice velocity of a previously unmapped part of a large icefield using pairs of SAR images collected by the SIR-C SAR instrument. The results illustrate the greater temporal stability of radar signals collected at the longer radar wavelengths, suggesting glacier research would greatly benefit from utilizing interferometric radars operating at the longer wavelengths. Long-wavelength radars also offer the possibility of monitoring larger strain rates, possibly at greater depths.

The topographic information retrieved from the SIR$\mathrm{C}$ interferometry data had a $10 \mathrm{~m}$ precision in height, less than expected, because the interferometric baselines were short and the instrument operated a single antenna. The precision in velocity was, however, sufficient to provide a complete view of the ice-flow dynamics of the glacier. Only a few scenes, similar to the one described here, would be necessary to cover the entire Patagonia Icefields. Such data would produce a major leap forward in our knowledge of the ice-flow dynamics of these regions and provide invaluable information on its current state of mass balance and its contribution to sea-level rise.

\section{ACKNOWLEDGEMENTS}

This work was undertaken at the Jet Propulsion Laboratory, California Institute of Technology, under a contract with the National Aeronautics and Space Administration. We should like to thank the people at the Jet Propulsion Laboratory, who process the SIR-C SAR data, Drs C. Werner and P. Rosen, for sharing their implementation of a phase-unwrapping program, Dr C. Warren for excellent comments on the manuscript and useful discussions, and Drs B. Kamb and H. Engelhardt, for discussions on the relevance of these results to studies of rapid glacial flow. We also thank the numerous colleagues who, in this exciting time of development, have spurred our understanding of the science of SAR interferometry through their open discussion, both formal and informal.

\section{REFERENCES}

Aniya, M. 1988. Glacier inventory for the Northern Patagonia Icefield, Chile, and variations $1944 / 45$ to $1985 / 86$. Arct. Alp. Res., 20 2), 179 187

Curlander, J. and R. McDonough. 1991. Synthetic aperture radar: systems and signal processing. New York, etc., John Wiley and Sons.

Evans, S. 1965. Dielectric properties of ice and snow-a review. 7. Glaciol., 5 (42), 773-792.

Fahnestock, M., R. Kwok and T.A. Scambos. 1994. Ice flow in the northeast Greenland ice stream. [Abstract.] EOS, $75(44)$, Supplement, 212.

Fatland, D. R. and C.S. Lingle. 1994. The surface velocity field on Bagley Icefield, Alaska, before and during the 1993-'94 surge of Bering Glacier, from ERS-1 SAR interferometry. [Abstract.] EOS, 75 (44), Supplement, 62.

Fujiyoshi, Y., H. Kondo, J. Inoue and T. Yamada. 1987. Characteristics of precipitation and vertical structure of air temperature in the northern Patagonia. Bull. Glacier Res. 4, 15-23.

Gabriel, A. K., R. M. Goldstein and H. A. Zebker. 1989. Mapping small elevation changes over large areas: differential radar interferometry. J. Geophys. Res., 94(B7), 9183-9191. 
Goldstein, R. M. 1995. Atmospheric limitations to repeat-track radar interferometry. Geophys. Res. Lett., 22 (18), 2517-2520.

Goldstein, R. M., H. A. Zebker and C. L. Werner. 1988. Satellite radar interferometry: two-dimensional phase unwrapping. Radio Sci., 23 4), $713-720$.

Goldstein, R. M., H. Engelhardt, B. Kamb and R. M. Frolich. 1993. Satellite radar interferometry for monitoring ice sheet motion: application to an Antarctic ice stream. Science, 262 (5139), 1525-1530.

Hartl, P., K. -H. Thiel, X. Wu, C. S. M. Doake and J. Sievers. 1994. Application of SAR interferometry with ERS-1 in the Antarctic. Earth Observation Quarterly, 43, 1-4.

Jezek, K. and E. Rignot. 1994. Katabatic wind processes on the Greenland ice sheet. [Abstract.] EOS, 75 (44), Supplement, 212.

Joughin, I. R. 1995. Estimation of ice-sheet topography and motion using interferometric synthetic aperture radar. (Ph.D. thesis, University of Washington.)

Joughin, I. R., D. P. Winebrenner and M. A. Fahnestock. 1994. Satellite radar interferometry observations of ice sheet motion in Greenland. [Abstract.] EOS, 75 44), Supplement, 223-224.

Joughin, I. R., D. P. Winebrenner and M.A. Fahnestock. 1995. Observations of ice-sheet motion in Greenland using satellite radar interferometry. Geophys. Res. Lell., 22 (5), 571-574.

Joughin, I., D. Wincbrenner, M. Fahnestock, R. Kwok and W. Krabill. 1996. Measurement of ice-sheet topography using satellite-radar interferometry. J. Glaciol., $42(140), 10-22$.

Kondo, H. and T. Yamada. 1988. Some remarks on the mass balance and the terminal-lateral fluctuations of San Rafael Glacier, the Northern Patagonia Icefield. Bull. Glacier Res, 6, 55-63.

Krimmel, R. M. 1992. Photogrammetric determinations of surface altitude, velocity, and calving rate of Columbia Glacier, Alaska, 1983 91. U.S. Geol. Surv. Open File Rep. 92-104.

Kwok, R. and M. Fahnestock. 1994. Determination of ice sheet motion and topography using radar interferometry. [Abstract.] EOS, 75 44), Supplement, 212.

Kwok, R. and M.A. Fahnestock. 1996. Ice-sheet motion and topography from radar interferometry. IEEE Trans. Geosci. Remote Sensing, GE-34 (1), $189-200$.

Li, F.K. and R.M. Goldstein. 1990. Studies of multi-baseline spaceborne interferometric synthetic aperture radars. IEEE Trans. Geosci. Remote Sensing, GE-28(1), 88-97.

Mätzler, C. 1987. Applications of the interaction of microwaves with the natural snow cover. Remole Sensing Rev., 2, 259-387.

Meier, M. F. and A. Post. 1987. Fast tidewater glaciers. J. Geophys. Res., 92 (B9), 9051-9058.

Naruse, R. 1985. Flow of Soler Glacier and San Rafacl Glacier. In Nakajima, C., ed. Glaciological studies in Patagonia Northern Icefield, 1983-1984. Nagoya, Japanese Society of Snow and Ice. Data Center for Glacier Research, 6469.

Reed, D. J., R. M. Wood and J. Best. 1988. Earthquakes, rivers and ice: scientific research at the Laguna San Rafael, southern Chile, 1986. Geogr. J., $154(3), 392-405$.

Rignot, E., K. C. Jezek and H. C. Sohn. 1994. Mapping glacial motion using radar interferometry. [Abstract.] EOS, $\mathbf{7 5}(44)$, Supplement, 212.

Rignot, E., K. C. Jezek and H. G. Sohn. 1995a. Ice flow dynamics of the Greenland ice sheet from SAR interferometry. Geophys. Res. Lett., 22(5), 575-578.

Rignot, E., R. Forster and B. Isacks. 1995b. SIR-C/X-SAR repeat-pass interferometry applications to Patagonian outlet glaciers. [Abstract.] EOS, 76 (17), Supplement, S196.

Rignot, E., R. Forster and B. Isacks. 1996. Mapping of glacial motion and surface topography of Hielo Patagónico Norte, Chile, using satellite SAR L-band interferometry data. Ann. Glaciol., 23, 209216.

Rodriguez, E. and J.M. Martin. 1992. Theory and design of interferometric synthetic aperture radars. IEE Proc., Ser. F, 139 (2), $147-159$.

Warren, C. R. 1993. Rapid recent fluctuations of the calving San Rafael Glacier, Chilean Patagonia: climatic or non-climatic? Geogr. Ann., 75A (3), 111-125.

Warren, C. R. and D. E. Sugden. 1993. The Patagonian icefields: a glaciological review. Arct. Alp. Res., 25 (4), 316-331.

Warren, C. R., N. F. Glasser, S. Harrison, V. Winchester, A. R. Kerı and A. Rivera. 1995. Characteristics of tide-water calving at Glaciar San Rafael, Chile. J. Glaciol., 41 (138), 273-289.

Yamada, T. 1987. Glaciological characteristics revealed by $37.6-\mathrm{m}$ deep core drilled at the accumulation area of San Rafael Glacier, the Northern Patagonia Icefield. Bull. Glacier Res. 4, 59-67.

Zebker, H.A. and R.M. Goldstein. 1986. Topographic mapping from interferometric synthetic aperture radar observations. f. Geophys.
Res., 91 (B5), 4993-4999.

Zebker, H.A. and J. Villasenor. 1992. Decorrelation in interferometric radar echoes. IEEE Trans. Geosci. Remole Sensing, GE-30 (5), 950-959.

Zebker, H.A., P. A. Rosen, R. M. Goldstein, A. Gabriel and C. L. Werner. 1994. On the derivation of coseismic displacement fields using differential radar interferometry: the Landers earthquake. $f$. Geophys. Res., 99 (B10), 19,617-19,634.

\section{APPENDIX}

If $\mathbf{a}_{1}$ and $\mathbf{a}_{2}$ denote, respectively, the complex amplitude (amplitude and phase) of the signal measured by antennae 1 and 2 during successive passes over the same pixel element, the normalized cross-products are computed as

$$
\rho_{21}=\frac{\left\langle\mathbf{a}_{1} \mathbf{a}_{2}^{*}\right\rangle}{\left\langle\left|\mathbf{a}_{1}\right|^{2}\right\rangle\left\langle\left|\mathbf{a}_{2}\right|^{2}\right\rangle} .
$$

The magnitude of $\rho_{21}$, denoted $\rho_{21}$, measures the temporal coherence of the phase between 0 no coherence) and 1 (perfect coherence) Zebker and Villasenor, 1992). The phase of $\rho_{21}$, denoted $\phi_{21}$, measures surface displacements in the line of sight of the radar according to (Zebker and others, 1994)

$$
\phi_{21}=4 \pi \lambda\left[B_{21} \cos \left(\alpha_{21}+\theta_{z}\right)+V_{\mathrm{r}} \delta t_{21}\right]+\phi_{21}^{\mathrm{o}},
$$

where $\lambda$ is the radar wavelength, $B_{21}$ is the baseline distance between antennae 2 and $1, \alpha_{21}$ is the base-line angle with horizontal, $\theta_{z}$ is the illumination angle with horizontal for a point at elevation $z$ (different definition from Zebker and others (1994)), $V_{\mathrm{r}}$ is the motion vector of ice in the line-of-sight of the radar, $\delta t_{21}$ is the time lag between the two images and $\phi_{21}^{\circ}$ is the absolute-phase offset. Following Zebker and others (1994), we flatten the phase as

$$
\begin{aligned}
\phi_{21, f l a t} & =\phi_{21}-4 \pi \lambda\left[B_{21}\left(\cos \left(\alpha_{21}+\theta_{0}\right)\right]-\phi_{21}^{\mathrm{o}}\right. \\
& =4 \pi \lambda\left[B_{21 \perp} \delta \theta_{z}+V_{\mathrm{r}} \delta t_{21}\right]
\end{aligned}
$$

where $B_{21 \perp}=B_{21} \sin \left(\alpha_{21}+\theta_{0}\right)$ is the perpendicular baseline, $\theta_{0}$ is the depression angle calculated for flat terrain $(z=0)$ and $\sin \left(\delta \theta_{z}\right) \approx \delta \theta_{z}$ because $\delta \theta_{z}=\theta_{z}-\theta_{0}$ is small. With two interferograms, we obtain the linearized system

$$
\begin{aligned}
& \phi_{21, \text { flat }}=4 \pi \lambda\left[B_{21 \perp} \delta \theta_{z}+V_{\mathrm{r}} \delta t_{21}\right] \\
& \phi_{23, \text { flat }}=4 \pi \lambda\left[B_{23 \perp} \delta \theta_{z}+V_{\mathrm{r}} \delta t_{23}\right] .
\end{aligned}
$$

Since $\delta t_{21}=-\delta t_{23}$, the topography term, $\delta \theta_{z}$, is obtained by summation of the two equations. The velocity term, $V_{\mathrm{r}}$, is obtained by reporting the estimated $\delta \theta_{z}$ into either one of the equations. Horizontal velocities are deduced from $V_{\mathrm{r}}$ using

$$
\begin{aligned}
& u_{x}=V_{\mathrm{r}} \frac{\cos \beta \cos \psi}{\cos \beta \cos \psi \sin \theta_{i}-\sin \beta \cos \theta_{i}} \\
& u_{y}=V_{\mathrm{r}} \cos \beta \sin \psi \cos \beta \cos \psi \sin \theta_{i}-\sin \beta \cos \theta_{\mathrm{i}}
\end{aligned}
$$

where $\beta$ is the surface slope counted positive downwards and calculated from the topography, $\psi$ is the angle between the horizontal flow vector and the $x$ axis (cross- 
track direction) and $\theta_{i}$ is the local incidence angle of the radar illumination (Rignot and others, 1995b; Kwok and Fahnestock, 1996). If the longitudinal axis $L$ is horizontal and parallel to the center line of the glacier, the longitudinal and transverse components of the velocity are

$$
\begin{aligned}
& u_{\mathrm{L}}=u_{x} \cos \left(\psi_{\text {cent }}\right)+u_{y} \sin \left(\psi_{\text {cent }}\right) \\
& u_{\mathrm{T}}=-u_{x} \sin \left(\psi_{\text {cent }}\right)+u_{\mathrm{y}} \cos \left(\psi_{\text {cent }}\right)
\end{aligned}
$$

where $\psi_{\text {cent }}$ is the flow direction along the center line. Surface strain rates are deduced using

$$
\begin{array}{r}
\dot{\epsilon}_{i j}=12\left(\partial u_{i} \partial j+\partial u_{j} \partial i\right),\{i, j\} \in\{L, T\} \\
\dot{\epsilon}_{\mathrm{ZZ}}=-\left(\dot{\epsilon}_{\mathrm{LL}}+\dot{\epsilon}_{\mathrm{TT}}\right) \\
\dot{\epsilon}_{\mathrm{e}}^{2}=12 \dot{\epsilon}_{i j} \dot{\epsilon}_{i j}
\end{array}
$$

$\dot{\epsilon}_{\mathrm{ZL}}$ and $\dot{\epsilon}_{\mathrm{ZT}}$ are assumed negligible. 